\title{
A Novel Placement Technique of S2 Screw (from S2 to Promontorium) and Double Screwing from S2
}

\author{
Sedat Dalbayrak¹, Ahmet Öğrenci ${ }^{1, \odot}$ \\ ${ }^{1}$ Department of Neurosurgery, Okan University, Istanbul, Turkey \\ 2Department of Neurosurgery, Haydarpasa Numune Training and \\ Research Hospital, Istanbul, Turkey \\ ${ }^{3}$ Department of Neurosurgery, Neurospinal Academia, Istanbul, \\ Turkey
}

\author{
Orkun Koban ${ }^{1, \odot ~ M e s u t ~ Y ı l m a z ~} 3, \odot$
}

\author{
Address for correspondence Ezgi Akar, MD, Department of \\ Neurosurgery, Haydarpasa Numune Training and Research \\ Hospital, Tibbiye Street, Uskudar, Istanbul 34668, Turkey \\ (e-mail: ezgiaycicek@gmail.com).
}

\begin{abstract}
Keywords

- S2 screw technique

- sacroiliac joint violation

- sacropelvic instrumentation
\end{abstract}

\section{Introduction}

Pseudoarthrosis in the lumbosacral region has been understood better as this region is treated more frequently and the results have become more apparent, while new researches have been performed to minimize the risk of pseudoarthrosis during surgical treatment. ${ }^{1}$ Instrumentations were developed on the sacrum and iliac wing, and thus enabled us to better understand the importance of anterior support. Since pseudoarthrosis is frequently seen in lumbosacral stabilizations ending in S1, S2 screws have been used more frequently to support S1. ${ }^{2,3}$ Lateral oriented S2 screw applications have also been included in the literature. In this technical article, we will try to explain the possibility of applying double screw from S2, as well as placing a screw in the medial and superior position (toward promontorium) from S2.

\section{Case Presentation}

A 63-year-old female patient had undergone surgery due to degenerative spine disease approximately 3 years ago. In the first period, a decrease has been observed in her complaints, but an increase in lower back pain was observed for the last 1 year. In the examination of the patient, pseudoarthrosis was diagnosed in the lumbosacral junction. Additionally, serious bone defects were observed in the patient's S1 screw holes (-Fig. 1A). Patient's low back pain Visual Analogue Scale (VAS) value was 10 and the Oswestry Disability Index (ODI) score was $86 \%$. Revision surgery was performed in the third year after the first operation. Since pseudarthrosis occurred despite the stabilization procedure by applying interbody cage with the rigid system and due to the possibility of pseudoarthrosis with rigid systems, the rigid system was removed published online April 19, 2021
DOI https://doi.org/

$10.1055 / \mathrm{s}-0041-1728987$ ISSN 2277-954X (c) 2021. Neurological Surgeons' Society of India.

This is an open access article published by Thieme under the terms of the Creative Commons Attribution-NonDerivative-NonCommercial-License, permitting copying and reproduction so long as the original work is given appropriate credit. Contents may not be used for commercial purposes, or adapted, remixed, transformed or built upon. (https://creativecommons.org/licenses/by-nc-nd/4.0/). Thieme Medical and Scientific Publishers Pvt. Ltd. A-12, 2nd Floor, Sector 2, Noida-201301 UP, India 


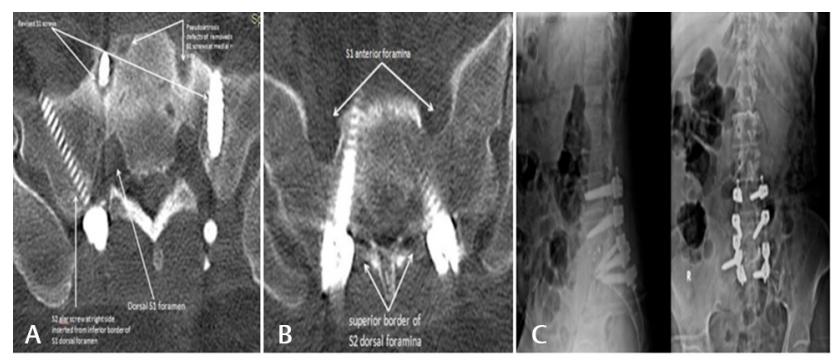

Fig. 1 Right S2 alar and S1 screws are seen at the postoperative computed tomography in axial section (A). Lateral and anteroposterior (AP) $\mathrm{X}$-rays demonstrate the screws in the stabilization system (B). Bilateral S2-promontorium screws are seen (C).

and dynamic stabilization was applied with polyetherketone rod (PEEK rod) (England Invibio, $6 \mathrm{~mm}$ diameter) at the revision surgery.

Peroperatively, the L5-S1 interbody PEEK cage was left in the $d$ level in the disc space.

\section{Treatment}

During the surgery, S1 screws were placed more perpendicularly due to loss of bone mass in the medial direction. The medical team decided to place the $\mathrm{S} 2$ screws through the promontorium. The screws were inserted bilaterally from $\mathrm{S} 2$ (from the superolateral border of S2 dorsal foramen) to the promontorium (-Fig. 1B). This point is approximately $2 \mathrm{~cm}$ below from the S1 transpedicular screw entry point, and the inferolateral side L5-S1 facet joint. There was no extra blood loss during the dissection of the muscle. Opening a little more of the fascia toward the inferior to $1 \mathrm{~cm}$ was sufficient. Extra equipment or navigation was not required and thus not used. Standard surgical transpedicular screw set was sufficient. However, for proper application, the screw route was checked gradually at each stage, and it was checked with probes whether bone tissue was present. While the S2 screws were medially oriented, the $\mathrm{S} 1$ screw halos (bone defects) were not encountered since the expanded S1 screw halos were located on the superior. There was no such halo already in the transition direction of S2-promontorium screws. On average, this screw application extended the surgical time to each screw press for approximately 5 to 10 minutes. One of the most frequently encountered problems in practice is sacral foramen insertion and sacral root injury. However, if the sacral anatomy and foramen sites were carefully detected with preoperative bleeding time, the application would be easier. If the patient anatomy and neural foramen do not allow this procedure, the option of applying S2 alar, S2 alar iliac (SAI), or iliac wing screw should be considered.

Peroperative manual examination revealed that the screw had strong grip. Afterward, additional S2 alar screw could be inserted from the inferolateral border of the S1 dorsal foramen at the right side ( $\mathbf{- F i g}$. 1B). Postoperative X-rays were uneventful ( - Fig. 1C). The patient's low back pain VAS value was 3 and ODI score was 36\% at postoperative first year follow-up. Although the patient underwent instrumentation with the dynamic system, there was no problem such as screw loosening in the postoperative 26th month with the strong stabilization provided by the newly applied screws ( - Fig. 2A, B). Beside this, fusion at the L5-S1 region was achieved. This suggests strong stabilization of S2-promontorium screws even with the dynamic system. Since our Research Ethics Board did not deem patient consent to be necessary, we did not include the patient's consent in this study.

\section{Discussion}

The complex anatomy of the lumbosacral region and the presence of more pseudoarthrosis than the upper lumbar regions are the most challenging reasons for revision surgeries. According to Kim et al, the single level of the rate of pseudoarthrosis in L5-S1 is $24 \% .^{1}$ Or failure rates have increased in surgical treatments without additional support for L5-S1 instrumentation. ${ }^{1-3}$ For this reason, solid fusions in the lumbosacral region is less frequent and pseudoarthrosis is more frequently encountered when compared with other levels. ${ }^{4}$ Sacropelvic instrumentation is known to require excess tissue dissection, prolong surgical time, and to increase infection rates. ${ }^{5,6}$ However, it is understood that the sacropelvic instrumentation is more necessary after the problems encountered after the 5-1 segment is added to the stabilization system. Therefore, in addition to providing interbody support in patients who underwent S1 instrumentation, either iliac wing or S2 screw placement has been an attempt to reduce the risk of pseudoarthrosis, to increase the chance of fusion. ${ }^{1,3,7,8}$ Placement of the iliac wing screw requires much more experience. It is more challenging than lumbar instrumentation. An offset connector may be needed. More muscle dissection and connective tissue removal is required. S2 screwing has been applied so far as S2 alar or SAI. ${ }^{9}$ The fact that the S2 alar screw is shorter and the SAI screw may provide stronger grip, it has also been reported that the SAI screw has a lower infection rate, requires less tissue dissection, and is more advantageous than the iliac wing screw since it allows for direct rod connection in comparison to the iliac wing screw. ${ }^{5,10}$ It has also been reported that the SAI screw provides strong support for kyphoscoliosis correction. ${ }^{11} \mathrm{~A}$ cadaver study was also performed to reveal that the SAI screw is partially easier to apply and the correct placement rate is high without radiographic support. ${ }^{5}$

However, the screws guided from S2 to the lateral direction causes sacroiliac joint violation and sacroiliac pain in the patients. This is a disadvantage for the S2 alar or SAI screws.
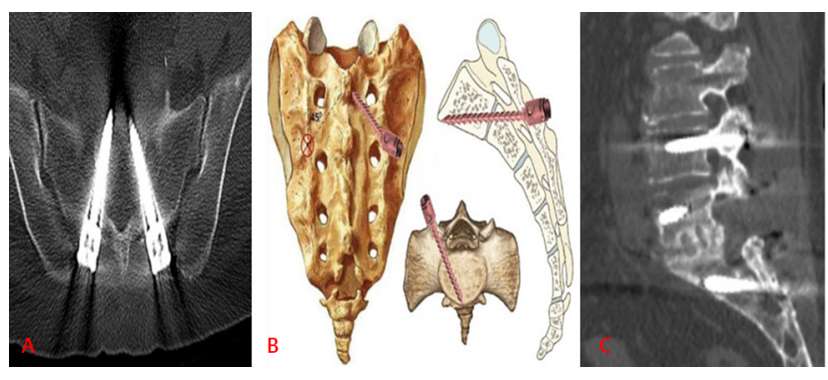

Fig. 2 In the axial computed tomography (CT) section (A), also in the sagittal CT section (B), no loosening was observed in the S2-promontorium screws. The demonstrative view of application of S2-promontorium screw fusion was observed at the L5-S1 level (C). 
Screws inserted from S2 were found to occupy sacroiliac joints by $60 \%{ }^{5}$ The long- and short-term effects of sacroiliac joint irritation are also unclear, but many patients may experience complaints of pain. We may avoid from this disadvantage by the screw orientation we have described above.

As it is known, it has been determined that the grip of the screws sent to the promontorium is quite strong. ${ }^{12,13}$ In screw implementation at $\mathrm{S} 1$, many authors suggest inserting it through the promontorium. However, screw from $\mathrm{S} 2$ to promontorium has not yet been described. Medially orientated screw from S2 has not been mentioned in the literature to date. As yet, the locations of the S2 screw placement have previously been shown with cadaver studies, in which dorsal foraminal widths and safe zones have been determined. ${ }^{14,15}$

The best place for S2 screwing is shown to be below the S1 dorsal foramen and above the S2 dorsal foramen. Because of the reduction of bone mass in the region where S1 screws were removed from the medial side in our patient, we applied the S1 screws a little more inferior and more neutral (perpendicular) with interbody support. However, to minimize the risk of a pseudoarthrosis, we have decided to change the rigid system to the dynamic system (with PEEK rod) and extend the stabilization. Because of the handicaps of the iliac or SAI screws on sacroiliac joint, we preferred to have a change of course. Instead, we applied a screw through to the sacral ala and at inferiomedial side of this screw, applied another screw though to the promontorium at the right side ( $6.5 \times 40 \mathrm{~mm}$ polyaxial). A screw could be inserted from $\mathrm{S} 2$ to the promontorium at left side $(6.5 \times 40 \mathrm{~mm}$ polyaxial $)$. The grip resistance of screws was assessed manually peroperatively. The grip resistances were quite strong. With this case, we tried to present a double screw from S2 and an alternative direction from $\mathrm{S} 2$ to the promontorium.

There are two points to be noted in the screw technique sent from S2 to the promontorium. It should not be forgotten that medial screws such as those in S1 may cause damage to the anterior sacral structures, and may result in hemorrhage, neurological damage, and chronic pain. ${ }^{13-15}$ Ebraheim et al have suggested that the screw from S2 should be sent laterally as much as possible. ${ }^{15}$ Besides, there are studies showing that the likelihood of risk of anteriorly located middle sacral artery, vein, and sacral sympathetic trunk damage is considerably high. ${ }^{13-15}$

Therefore, when the screw is considered to be inserted from S2 to the promontorium, absolutely angular measurements should be evaluated and longer screw placement should be avoided. Bicortical screwing should not be forced. One of the other important points is to pay attention to the anterior sacral foramen. Anterior S1 foramina should be at the lateral side of the placed S2-promontorium screws. For this reason, the screw can be placed up to 45-degree angle to the neural foramen as well as at a 5- to 10-degree superior position than the neutral prone position through the promontorium ( - Fig. 2 C).
Screw placement from S2 to the promontorium is convenient for both rod connection and helps to avoid sacroiliac joint violation and reduces the need for iliac wing screws and tissue dissection. It may be a new alternative for sacral instrumentation. Further biomechanical and cadaver studies will be more enlightening in terms of grip strength.

\section{Funding}

None.

\section{Conflict of Interest}

None declared.

\section{References}

1 Kim YJ, Bridwell KH, Lenke LG. Cho KJ, Edwards CC II, Rinella AS. Pseudarthrosis in adult spinal deformity following multisegmental instrumentation and arthrodesis. J Bone Joint Surg Am 2006;88(4):721-728

2 Xu R, Ebraheim NA, Douglas K, Yeasting RA. The projection of the lateral sacral mass on the outer table of the posterior ilium. Spine 1996;21(7):790-794, discussion 795

3 Edwards CC II, Bridwell KH, Patel A, Rinella AS, Berra A, Lenke LG. Long adult deformity fusions to L5 and the sacrum. A matched cohort analysis. Spine 2004;29(18):1996-2005

4 O'Brien JR, Yu WD, Bhatnagar R, Sponseller P, Kebaish KM. An anatomic study of the S2 iliac technique for lumbopelvic screw placement. Spine 2009;34(12):E439-E442

5 Martin CT, Witham TF, Kebaish KM. Sacropelvic fixation: two case reports of a new percutaneous technique. Spine 2011;36(9):E618-E621

6 Elder BD, Ishida W, Lo SL, et al. Use of S2-alar-iliac screws associated with less complications than iliac screws in adult lumbosacropelvic fixation. Spine 2017;42(3):E142-E149

7 Lebwohl NH, Cunningham BW, Dmitriev A, et al. Biomechanical comparison of lumbosacral fixation techniques in a calf spine model. Spine 2002;27(21):2312-2320

8 Tsuchiya K, Bridwell KH, Kuklo TR, Lenke LG, Baldus C. Minimum 5-year analysis of L5-S1 fusion using sacropelvic fixation (bilateral S1 and iliac screws) for spinal deformity. Spine 2006;31(3):303-308

9 Sponseller P. The S2 Portal to the ilium. Semin Spine Surg 2007;2:83-87

10 Kebaish KM. Sacropelvic fixation: techniques and complications. Spine 2010;35(25):2245-2251

11 Liu Z, Qiu Y, Yan H, et al. S2 alar-iliac fixation: a powerful procedure for the treatment of kyphoscoliosis. Orthop Surg 2016;8(1):81-84

12 Okutan O, Kaptanoglu E, Solaroglu I, Beskonakli E, Tekdemir I. Determination of the length of anteromedial screw trajectory by measuring interforaminal distance in the first sacral vertebra. Spine 2004;29(15):1608-1611

13 Luk KD, Chen L, Lu WW. A stronger bicortical sacral pedicle screw fixation through the s1 endplate: an in vitro cyclic loading and pull-out force evaluation. Spine 2005;30(5):525-529

14 Arman C, Naderi S, Kiray A, et al. The human sacrum and safe approaches for screw placement. J Clin Neurosci 2009;16(8): 1046-1049

15 Ebraheim NA, Lu J, Yang H, Heck BE, Yeasting RA. Anatomic considerations of the second sacral vertebra and dorsal screw placement. Surg Radiol Anat 1997;19(6):353-357 